\title{
3 Der Ullstein-Verlag während des Nationalsozialismus (1933-1945)
}

\subsection{3: Die Gleichschaltung des Unternehmens}

Hermann Ullstein hatte noch im New Yorker Exil deutliche Erinnerungen an die Zeit direkt nach der Machtergreifung: „Am nächsten Tag, dem 31. Januar 1933, ist die Stimmung im Verlag an der Kochstraße sehr angespannt. Geregelte Arbeit scheint unmöglich. Die Leute stehen in den Korridoren herum, reden miteinander, streiten sich. Die Pessimisten sagen das Ende des Verlags voraus. Die Optimisten betrachten Hitlers Sieg als ein Zwischenspiel vor seinem nahen Sturz. “1 An diesem Dienstag verweigerte man Prof. Ludwig Stein, dem diplomatischen Berichterstatter der Vossischen Zeitung, und seinem Kollegen Max Reiner erstmals den Zutritt zur Reichskanzlei. ${ }^{2}$

Einer bloßen Enteignung des Ullstein-Imperiums standen dessen weltweites Renommee und sein herausragender wirtschaftlicher Wert entgegen. Die NSDAP, deren parteieigene Presse zum Stichtag der Machtergreifung lediglich 2,5 \% der deutschen Zeitungsauflagen ausmachte, setzte eher auf eine Erhöhung des Drucks auf Ullstein, um das Unternehmen nachhaltig zu schwächen und so eine „Arisierung“ zu erleichtern. ${ }^{3}$

Am 4. Februar 1933 wurde die „Verordnung des Reichspräsidenten zum Schutz des deutschen Volkes“ in Kraft gesetzt; vor allem deren Paragraphen 7 und 9 - auch bekannt als „Schubladenverordnungen“ - gaben den Behörden Möglichkeiten zur Unterdrückung von Presseunternehmen. ${ }^{4}$ Zahlreiche Verbote gegen Publikationen der KPD und der SPD waren die Folge. Die Maßnahme des neuen Kabinetts sollte zweifelsohne den Wahlkampf der Opposition für den Urnengang am 5. März behindern.

$\mathrm{Zu}$ den quasi über Nacht verbotenen Zeitungen gehörte auch Ullsteins Tempo: Zwischen Freitag, dem 17. Februar, und Freitag, dem 24. Februar 1933, durfte die Tageszeitung nicht vertrieben werden. Gegen das Verbot hatte der Ullstein-Verlag erfolgreich Beschwerde beim Reichsgericht eingereicht. Offiziell hatte sich die Zeitung der „bewussten falschen Darstellung der Börsentendenz“ schuldig gemacht. Tatsächlicher Anlass des Verbots aber dürfte die Berichterstattung auf der Tempo-Titelseite vom 16. Februar über die Störung eines Hit-

1 Vgl. Ullstein, Haus Ullstein, S. 23.

2 Siehe Mendelssohn, Zeitungsstadt, S. 474.

3 Hierzu Lindner, Arisierung, S. 75.

4 Siehe Koszyk, Deutsche Presse 1914-1945, S. 354.

๖ Open Access. () 2020 Juilane Berndt, publiziert von De Gruyter. (๕) By Dieses Werk ist lizenziert unter der Creative Commons Attribution-NonCommercial-NoDerivatives 4.0 License. 
ler-Auftritts in Stuttgart gewesen sein: Unbekannte Täter hatten per Axt einige Kabel gekappt und so die Rundfunkübertragung der Veranstaltung kurzzeitig unterbrochen. ${ }^{5}$ Wenn das Verbot einer einzelnen Tageszeitung die Ullstein AG wirtschaftlich auch nicht so stark erschüttern konnte wie es bei den Verlagen der kleineren oder parteigebundenen Blätter der Fall war, so deutete sich hier bereits die Vorgehensweise der Nationalsozialisten gegen das ,jüdische“ Unternehmen Ullstein an: Wirtschaftliche Einbußen, die aus politischen Zwangsmaßnahmen resultieren, sollten die Firma nachhaltig schwächen.

Mühelos übertroffen wurden die Auswirkungen der Notverordnung vom 4. Februar 1933 von der Verbotswelle gegen die Presse nach dem Reichstagsbrand vom 27. Februar. Die Notverordnung vom 28. Februar 1933 sah in ihrem Paragraph 1 Beschränkungen des Rechts auf Meinungsfreiheit und der Pressefreiheit auch außerhalb der bestehenden gesetzlichen Grenzen vor. In Preußen etwa waren neben dem Vorwärts u. a. das Acht-Uhr-Abendblatt, das Berliner Tageblatt, die Weltbühne und Der Jungdeutsche betroffen. ${ }^{6}$ Zudem kam es zu zahlreichen Verhaftungen, die Familie Ullstein traf es hier gleich zweimal.

Unmittelbar nach den Reichstagswahlen am 5. März 1933 wurde Heinz Ullstein, der Sohn von Louis und als Aufsichtsratsmitglied verantwortlich für den Tageszeitungsbereich, in seinem Haus von der SA verhaftet. Das angeheiratete Familienmitglied Fritz Ross, Schwiegersohn von Hans Ullstein, konnte ihn jedoch nach wenigen Stunden aus dem Gefängnis wieder abholen. ${ }^{7}$ Kurt Ullstein, der einzige Sohn von Franz Ullstein, erhielt in diesen Tagen zahlreiche anonyme Briefe, die ihm unter Drohungen nahelegten ins Ausland zu gehen. ${ }^{8}$ Als Kurt Ullstein dann tatsächlich am 21. März die deutsch-österreichische Grenze passierte, wurde er verhaftet: Anlass war laut Protokoll der Bayerischen Politischen Polizei, dass sein Chauffeur bei einem Zwischenstopp in München unbe-

5 Mendelssohn, Zeitungsstadt, S. 477 f., macht die Kombination aus dieser Meldung und einem direkt daneben platzierten Artikel über einen gescheiterten Attentatsversuch in Miami auf den ebenfalls frisch ins Amt getretenen Roosevelt als Anlass des Verbots aus.

6 Siehe Koszyk, Deutsche Presse 1914-1945, S. 357.

7 Vgl. Eidesstattliche Erklärung von Fritz Ross, abgegeben am 31.07.1951, in: AS-UA, Bestand Ullstein, Band 17: „Heinz Ullstein, der einzige Sohn von Louis Ullstein und Mitglied unseres Aufsichtsrates, wurde von der SA aus seinem Hause gezerrt und weggeschleppt. Als wir davon erfuhren, ging ich zu dem obersten Führer der Berliner SA, Prof. von Arnim, den ich seit dem kleinen Weltkrieg kannte, in die Hedemannstraße und erreichte die Freilassung von Heinz Ullstein.“ Die Gauleitung der NSDAP war 1930 von Charlottenburg in die Kreuzberger Hedemannstr. 10 umgezogen.

8 Eidesstattliche Erklärung von Fritz Ross, abgegeben am 31.07.1951, in: AS-UA, Bestand Ullstein, Band 17. 
kannten Dritten von einem „politischen Flüchtling“ berichtet hatte, den er samt eines großen Geldbetrags nach Österreich bringen sollte. ${ }^{9}$

Die hiernach eingeschaltete Münchener Polizei kontaktierte ihre Tiroler Kollegen, da man annahm, dass derjenige, der die Grenze mit dem Pass von Kurt Ullstein überquert habe, eigentlich ein von der Polizei gesuchtes Subjekt sei; seitens der Behörden ging man sogar davon aus, dass es sich dabei um einen der Täter des Reichstagsbrands handeln könnte. Kurt Ullstein wurde daraufhin in Reutte (Tirol) verhaftet und in Schutzhaft verbracht. Erst einer der UllsteinVertreter in Wien und der eilig angereiste Leiter der Buchhaltung der Ullstein AG, Gustav Willner, konnten Kurt Ullsteins Gefängnisaufenthalt beenden. ${ }^{10}$

In diesen März-Tagen kam es auch zur offenen Sabotage seitens der Nationalsozialisten: Die Vertriebs-Filialen des Verlags im Berliner Umland, etwa in Finsterwalde, Frankfurt/Oder, Cottbus etc. wurden überfallen, die Pakete mit Ullstein-Zeitungen und -Zeitschriften aus den Eisenbahnzügen herausgeholt und vernichtet. ${ }^{11}$ In Berlin gingen „Braunhemden“ straßenweise von Haus zu Haus, um die Bezieher der Berliner Morgenpost zu nötigen, ihr Abonnement aufzugeben, und stattdessen den Völkischen Beobachter $\mathrm{zu}$ beziehen. ${ }^{12}$ SA-Leute versuchten, Passanten zum „Sturm“ auf das Ullstein-Haus zu ermuntern. Als Reaktion darauf stattete man die Eingänge in der Kochstraße mit Fallgittern aus, die bei Bedarf per Knopfdruck zum Schutz der Mitarbeiter heruntergelassen werden konnten. ${ }^{13}$ Doch der Gegner saß bereits im Haus: Mitte März war eine Nationalsozialistische Betriebszellenorganisation (NSBO) gegründet worden. ${ }^{14}$ Am 30. März hatte der Stadtkommissar für Berlin, Lippert, den städtischen Dienststellen zudem verboten, Anzeigen an die ,jüdische Presse Berlins“ $\mathrm{zu}$ vergeben. ${ }^{15}$

9 Kurt Ullstein hatte offenbar tatsächlich versucht, zu fliehen, nachdem man ihm wie seinem Cousin Heinz eine baldige Verhaftung androhte. Siehe hierzu Schilderungen der Umstände 1933/34 im Klageantrag auf Restitution bei der 42. Wiedergutmachungskammer des Landgerichts Berlin, eingereicht am 09.08.1951, in AS-UA, Bestand Ullstein, Band 17.

10 Abschrift der Befragung von Gustav Willner vom 31.03.1933 durch die Bayerische Politische Polizei in AS-UA, Bestand Ullstein, Band 1.

11 Siehe hierzu „Eidesstattliche Erklärung“ von Fritz Ross vom 31.07.1951, in: AS-UA, Bestand Ullstein, Band 17.

12 Aus einem Brief Rudolf Ullsteins an das „Denacifierungsgericht in München“ vom 17.12.1948, in: AS-UA, Bestand Ullstein, Band 16.

13 Vgl. Bannehr, Eule, S. 44.

14 Dazu Bannehr, Eule, S. 46.

15 Rundverfügung des Stadtkommissars an die städtische Verwaltung, die Bezirksämter und die städtischen Gesellschaften, zitiert bei: Gruner, Wolfgang: Judenverfolgung in Berlin 19331945. Eine Chronologie der Behördenmaßnahmen in der Reichshauptstadt. Hrsg. von der Topographie des Terrors Berlin. Berlin 2009, S. 58. 
Der Druck wurde größer und die Mitglieder des Hauses Ullstein beschlossen, weitere Konzessionen gegenüber den Nationalsozialisten zu machen.

Am 20. März 1933 verstarb mit Louis Ullstein der zweitälteste der fünf Ullstein-Brüder. Am gleichen Tag nahm man verlagsintern Umbesetzungen in Vorstand und Aufsichtsrat vor. Bereits unmittelbar nach der Reichstagswahl vom 5. März hatte das Reichspropagandaministerium von Ullstein die Entlassung des bisherigen Generaldirektors Hans Schäffer, der erst im Juni 1932 eingestellt worden war, verlangt. Mit dieser Aufforderung ging die Androhung erneuter Zeitungsverbote einher. ${ }^{16}$

Die wichtigste Veränderung war die Berufung des „Ariers“ Richard A. Müller zum Vorstandsvorsitzenden. ${ }^{17}$ Den Vorsitz des Aufsichtsrats übernahm Dr. Ferdinand Bausback, sein Stellvertreter wurde Fritz Ross, der „arische“ Schwiegersohn von Hans Ullstein. In die Geschäftsführung trat zudem der Politische Direktor Dr. Eduard Stadtler ein. Von nun an setzten sich die zu weit reichenden Machtbefugnissen gelangten Direktoren Müller und Stadtler für die Vertreibung jüdischer Journalisten aus dem Ullstein-Haus ein. Vor allem mit dem neuen Vorstandschef Müller hatten sich die Ullsteins einen internen Feind geschaffen, der nicht vorhatte, lediglich als Strohmann der Eigentümer $\mathrm{zu}$ fungieren. ${ }^{18}$ Nach einer Unterredung mit Joseph Goebbels im Reichspropagandaministerium Anfang April 1933, wo man Müller mitgeteilt hatte, dass die vollständige „Arisierung“ der Ullstein AG der persönliche Wunsch Hitlers sei, ging der neue Vorstandsvorsitzende mit großem Eifer dazu über, jüdische oder andere unliebsame Redakteure mit möglichst kaum oder gar keiner Abfindung des Hauses zu verweisen. ${ }^{19}$

Von dem von den neuen Machthabern ausgerufenen „Judenboykott“ vom 1. April 1933 waren Zeitungsverlage formal ausgenommen, trotzdem marschierten mehrere Dutzend Mitarbeiter drei Stunden lang durch das Haus in der Kochstraße und skandierten antisemitische Parolen. ${ }^{20}$ In den darauffolgenden Tagen erfuhr die hausinterne Nationalsozialistische Betriebszellenorganisation einen deutlichen Zulauf, an einer „Fahnenweihe“ zum Monatsende, die in Treptow

16 Hierzu Münzel, Wirtschaftselite, S. 397.

17 Siehe Lindner, Arisierung, S. $75 \mathrm{f}$.

18 Im Exil fasste Hermann Ullstein zusammen: „My bitterest disappointment was Richard A. Müller“, in: Saturday Evening Post, Hitler, S. 12.

19 Vgl. Bannehr, Eule, S. 50.

20 Hermann Ullstein erinnert sich: „Mein Sekretär zog mich zurück ins Büro. Reporter tauchten auf mit bleichen Gesichtern. Unter den Marschierenden waren einige Bekannte: ein Zeichner, ein Fotograf, drei von unseren Schriftsetzern, ein paar Drucker und einige Redakteure. Die ganze Meute wurde angeführt von einem unserer Portiers, der immer in Habachtstellung gegangen war, wenn mein Wagen vorfuhr.“ Ullstein, Haus Ullstein, S. 38. 
abgehalten wurde, nahmen bereits 1.200 Personen teil. ${ }^{21}$ Ebenfalls Ende April fand eine Redaktionsversammlung im Casinosaal der Kochstraße statt, bei der allen jüdischen Redakteuren mitgeteilt wurde, dass sie das Unternehmen zu verlassen hätten.

Von da an sahen sich in den folgenden Monaten langjährige führende Mitarbeiter und Redakteure wie Carl Misch, BIZ-Chef Kurt Szafranski, Moritz Goldstein (alias Gerichtsreporter „Inquit“ von der Vossischen Zeitung) oder der Buchverlags-Direktor Emil Herz genötigt, Ullstein zu verlassen. Selbst die für die technischen Fragen zuständigen Familienmitglieder wie Rudolf Ullstein oder Franz' Schwiegersohn Kurt Saalfeld verließen bis zum November 1933 den Verlag. Max Reiner, ein politischer Redakteur bei der Vossischen Zeitung, erinnerte sich später im Exil in Palästina:

Ende April [1933, d. Verf.] erfuhren wir, dass die Entlassung aller jüdischen Redakteure beabsichtigt sei. Eine Versammlung der christlichen Redakteure wurde einberufen, die den Beschluss fasste, durch eine Abordnung bei der Verlagsdirektion gegen diese Absicht Einspruch zu erheben. Vom Generaldirektor wurde eine ausweichende Antwort gegeben. Zwei Tage darauf hörte ich auf den Korridoren lautes Rufen und Stampfen. Es war ein Demonstrationszug, der meist aus Angehörigen des Aufnahmesekretariats bestand. Es wurde gerufen: ,Juden hinaus!‘. Ich hörte auch meinen Namen. Zwei Stunden später wurde mir eine vervielfältigte Verlagmitteilung überreicht, in der aufgezählt wurde, welche jüdischen Redakteure und höheren Angestellten bereits entlassen seien und mit welchen wegen ihres Ausscheidens verhandelt werde. In der Liste befand sich auch mein Name. ${ }^{22}$

Am 13. Oktober 1933, exakt eine Woche, nachdem das sogenannte „Schriftleitergesetz“ verabschiedet wurde ${ }^{23}$, sandte der Politische Direktor Eduard Stadtler ein Schreiben an die Reichskanzlei, in dem er sich brüsten konnte, dass von der „personalpolitischen Umstellung“ bereits lang gediente wichtige Ullstein-Mitarbeiter betroffen seien: Etwa 70 Ullstein-Redakteure, mithin etwa jeder Dritte, seien entlassen worden. ${ }^{24}$

Trotz des erzwungenen Exodus’ zahlreicher „nichtarischer“ Mitarbeiter, die Ullstein mit ihrem Engagement zu seiner Größe mitverholfen hatten, war der

21 Siehe Bannehr, Eule, S. 46.

22 Aus: Reiner, Max: Mein Leben in Deutschland vor und nach dem Jahr 1933, Auszug, verfasst in Palästina 1940, in: Richarz, Monika (Hrsg.): Jüdisches Leben in Deutschland. Bd. 3: Selbstzeugnisse zur Sozialgeschichte 1918-1945. Stuttgart 1982. S. 109-119, hier S. 116 f.

23 Für den Juni 1933 wird in der Berufsgruppe „Redakteure, Schriftsteller“ ein Anteil Deutscher jüdischen Glaubens von ca. $5 \%$ angenommen, absolut entsprach dies 872 Personen. Zahlen nach Richarz, Jüdisches Leben, S. 24.

24 Siehe hierzu: Kempner, Robert M. W.: Hitler und die Zerstörung des Hauses Ullstein. Dokumente und Vernehmungen. In: Hundert Jahre Ullstein 1877-1977. Band 3. Hrsg. von Joachim W. Freyburg u. Hans Wallenberg. Frankfurt a. M./Berlin/Wien 1977. S. 267-292, hier S. 276. 
Verlag, genauer dessen Aktien, noch zu $100 \%$ in der Hand der fünf UllsteinBrüder (bzw. im Fall des verstorbenen Louis im Besitz seines Stammes).

Eduard Stadtler hatte am 12. Juli 1933 persönlich bei Hitler vorgesprochen, um über den Stand der politischen und finanziellen Gleichschaltung des Verlags zu berichten. Am 21. August verfasste der Politische Direktor ein Schreiben an Hitlers Staatssekretär Hans Heinrich Lammers ${ }^{25}$, in dem Stadtler nicht nur auf seine Besprechung mit Hitler einging, sondern auch von seinen Unterredungen mit Reichsbankpräsident Hjalmar Schacht berichtete: „Bei diesen Verhandlungen sollte der Herr Reichsbankpräsident feststellen, ob die beabsichtigten Maßnahmen dazu geeignet sind, den bisherigen personell und kapitalmäßig ausschlaggebenden Einfluss der Herren Ullstein zu beseitigen und eine Umstellung der kapitalmäßigen und wirtschaftspolitischen Führung der Betriebe im Sinne des neuen Staats zu gewährleisten." Wenige Tage später erteilte Lammers dem Reichsbankpräsidenten die Anweisung, eine Einschätzung über die Folgen der „Arisierung“ von Ullstein-Aktien abzugeben: „Im Auftrag des Herrn Reichskanzlers darf ich Sie ergebenst um Abgabe eines Gutachtens in der Frage bitten und wäre Ihnen dankbar, wenn Sie das Gutachten außer dem Herrn Reichskanzler sowie dem Herrn Reichsminister für Volksaufklärung und Propaganda Dr. Goebbels zuleiten würden.“ ${ }^{26}$

Das Gutachten des Reichsbankpräsidenten war am 29. September 1933 fertig. Schacht führte darin zunächst aus, dass die Pläne zur Kapitalumlagerung mit dem Vorstandsmitglied Dr. Ferdinand Bausback, der früher in Stuttgart die Filiale der Deutschen Bank geleitet hatte, durchgesprochen worden seien. Ihre Absicht war eine breitgefächerte Verteilung der Ullstein-Aktien in den Portefeuilles bedeutender deutscher Industrie- und Handelsunternehmen. ${ }^{27}$

In finanzieller Hinsicht zielte Schacht somit auf eine größere Umverteilung $a b$ :

Damit würden Einfluss und Übergewicht der arischen Aktionärsgruppe gesichert sein, in deren Händen nach der Umbildung 4,5 Millionen RM von acht Millionen RM insgesamt vereinigt wären. [...] Im Besitze der Familie Ullstein würde dagegen nach der vorgesehenen Aktieneinziehung und der Umwandlung von vier Millionen RM Aktien in Genussscheine ohne Stimmrecht nur noch ein Betrag von 3,5 Millionen RM Aktien verbleiben. Dieser Besitz stellt die Minderheit dar und soll noch dadurch besonders gebunden werden, dass er durch einen arischen Treuhänder verwaltet wird, der auch das Stimmrecht in

25 Kempner, Hitler, S. 272.

26 Schreiben von Staatssekretär Hans Heinrich Lammers an Hjalmar Schacht vom 24.08.1933, Kempner, Hitler, S. 273.

27 Siehe hierzu James, Harold: Die Deutsche Bank und die „Arisierung“. München 2001, S. 49. James bezeichnet den Fall Ullstein auch als „[d]as drastischste Beispiel unter denen, an denen die Deutsche Bank beteiligt war...“ (S. 48). 
der Generalversammlung auszuüben hat. Der Einfluss der Familie Ullstein soll finanziell ferner noch dadurch wesentlich verringert werden, dass die satzungsgemäß den alten Gründern der Firma zustehende Vergütung in stimmrechtlose Gründergenussscheine umgewandelt, also damit fest gebunden, wird, und dass zugleich die Gründer sich unwiderruflich verpflichten müssen, einen Teil ihrer Aktien oder Genussscheine an den Jubiläumspensionsfonds ${ }^{28}$ abzugeben, der ausschließlich sozialen Bestrebungen zugunsten der Arbeitnehmer dient. ${ }^{29}$

Neben dieser vorgesehenen finanziellen Enteignung sah das Schacht-Gutachten auch Parameter für personelle Umbesetzungen und für die Vorgehensweise nach vollzogener „Arisierung“ vor:

Aus dem Vorstand würden bis auf ein Mitglied der Familie Ullstein [gemeint ist wohl Fritz Ross, d. Verf.] die Nichtarier, auch soweit sie zu dieser Familie gehören oder mit dieser verwandt sind, ausscheiden und durch Arier ersetzt werden. [...] Von gewisser Bedeutung ist schließlich noch die Frage der weiteren Firmenführung. Mit Rücksicht auf die wirtschaftliche Tragweite für die künftige Entwicklung des Unternehmens, mit der die Geschicke der zahlreichen Arbeitnehmerschaft verbunden sind, geben wir anheim, von einer Ausmerzung des Namens Ullstein aus der Firma abzusehen.

Auf das Gutachten Schachts verfasste der Aufsichtsratsvorsitzende Bausback am 12. Oktober ein Schreiben an die Reichskanzlei, in dem er zusicherte, dass „der Plan in der der Reichsbank vorgelegten Form nunmehr unverzüglich zur Durchführung gelangt““. ${ }^{30}$ Auch das einen Tag später verfasste, oben bereits zitierte Schreiben des Politischen Direktors Stadtler an die Reichskanzlei, ging auf die Umsetzung des Schacht-Plans ein:

\begin{abstract}
Soweit die Neuorientierung aktienrechtlich gedacht war, sind die Maßnahmen inzwischen praktisch bis zu dem Punkt gediehen, dass ein von den maßgebenden neuen Herren des Hauses ausgearbeiteter Vorschlag zur aktienrechtlichen Umlagerung des Ullsteinbesitzes nach Begutachtung durch das Reichsbankpräsidium nunmehr den zuständigen Stellen vorgelegt worden ist.
\end{abstract}

Diese vorsichtige Wortwahl über die Umsetzung des Schacht-Gutachtens scheint angemessen, sieht man die Konsequenzen, die die Ullsteins daraus in den folgenden Tagen dann tatsächlich zogen: Anstatt der geforderten 4,5 Mio. Aktien löste die Familie im Oktober lediglich Aktien im Nennwert von 1 Mio. RM aus ihrem Besitz und übertrug diese unentgeltlich - gleichwohl mit der Option

28 Der Ullstein-Verlag hatte anlässlich seines 50-jährigen Bestehens 1927 einen Pensionsfonds für seine Mitarbeiter in Höhe von 1 Mio. RM gegründet. Siehe Axel Springer Verlag, 125 Jahre Ullstein, S. 145.

29 Das Gutachten Hjalmar Schachts vom 29.09.1933 bei Kempner, Hitler, S. 274.

30 Schreiben Ferdinand Bausbacks an Adolf Hitler vom 12.10.1933 in Kempner, Hitler, S. 275. 
des Rückerwerbs gegen ein Aufgeld - an eine überschaubare Anzahl „arischer“ Bekannter. ${ }^{31}$ Womit auch die von Hjalmar Schacht angedachte weite Streuung des Kapitals auf diverse Industrie- und Handelsfirmen zu diesem Zeitpunkt weitgehend unterbunden werden konnte.

Unterdessen war die Liquidität des Verlags unter den Folgen der anhaltenden Boykottmaßnahmen zunehmend eingeschränkt. Vor diesem Hintergrund erschien es Ullstein sinnvoll, sein Portfolio zu verringern. Gleichwohl konnte man sich 1933 noch nicht dazu entschließen, das größte Zuschussobjekt des Verlags, die Vossische Zeitung, einzustellen. Stattdessen fiel die Wahl auf eine andere Zuschussunternehmung ohne vergleichbare Tradition: die Tageszeitung Tempo. Die Nummer 174 des 6. Jahrgangs vom 5. August 1933, einem Samstag, war die letzte Ausgabe der 1928 gestarteten Tageszeitung. ${ }^{32}$

Doch auch bei der Vossischen Zeitung bemühte man sich um finanzielle Schadensbegrenzung, ab dem 1 . November 1933 erschien das altehrwürdige Traditionsblatt mit nur noch einer Ausgabe am Tag; die Abendexpedition wurde gestrichen, die Morgenausgabe entsprechend erweitert.

Bereits im April war letztmalig das elitäre Vorzeigeblatt der Weimarer Jahre, der Querschnitt, unter der Ägide Ullsteins erschienen. Im Gegenzug wurde ab November 1933 - auch dies ist als Konzession an das NS-Regime zu sehen - die vom Reichsluftschutzbund herausgegebene amtliche Zeitschrift Die Sirene übernommen..$^{33}$

31 Siehe hierzu James, Deutsche Bank, S. $48 \mathrm{f}$. Zuvor war das Stammkapital der Ullstein AG von 10 auf 6 Mio. RM herabgesetzt worden, indem 4 Mio. stimmlose Genussscheine geschaffen worden waren. Die Familie behielt die Obligationen und einen Teil des Stammkapitals und von diesen 6. Mio. RM wurde dann 1 Mio. RM in Tranchen von 100.000 und 200.000 RM an Bekannte der Familie Ullstein gegen spätere Abrechnung angeboten. Vgl. hierzu Stellungnahme von Gustav Willner vom 18.03.1946, in: AS-UA, Bestand Ullstein, Band 16. Bei den Aktienempfängern handelte es sich u. a. um Generaldirektor Dr. Debach von der Württembergischen Metallwarenfabrik, die Rittergutbesitzer von Wulffen und Friedrich Karl von Rohr, Dora Freifrau von Gemmingen-Hornberg, den Textilunternehmer Heinrich Pferdmenges und den Geopolitiker Karl Haushofer. Auflistung nach Mendelssohn, Presse gefesselt, S. 209.

32 Die Zeitung verabschiedete sich von ihren verbliebenen etwa 106.000 Käufern in einem Kasten auf Seite 4 unten so kurz und bündig, wie sie es als ihre Mission angesehen hatte: „Das ,Tempo“ sieht seine Aufgabe als beendet an; es stellt somit das Erscheinen mit der heutigen Nummer ein.“

33 Siehe Lindner, Arisierung, S. 77. 


\subsection{4: Verbote und Zwangsverkauf}

Mit dem Januar 1934 begann ein neuer Abschnitt im Ringen der Ullstein AG mit dem NS-Regime. Die bisherigen schrittweisen Gleichschaltungsmaßnahmen, die sich personell auf die untere, mittlere und gehobene Verwaltungs-, nicht aber die oberste Führungsebene auswirkten, waren der Reichskanzlei nicht konsequent genug - auch die in den Augen des NS-Regimes deutlich zu gering ausgefallene Streuung des Aktienkapitals rief keine Begeisterung hervor. Das neue Ziel, verfolgt durch den Reichspressekammer-Präsidenten Max Amann und Reichspropagandaminister Goebbels, war nun die Inbesitznahme des gesamten Ullstein-Unternehmens. Es sollte dem NS-eigenen Franz Eher Verlag, dem Amann ohnehin vorstand, einverleibt werden. ${ }^{34}$

Zudem spitzte sich die wirtschaftliche Situation zum Jahresbeginn 1934 für den Verlag zu. ${ }^{35}$ In seinen Erinnerungen schrieb Hermann Ullstein: „Frühling 1934. Das Klima von Denunziation, Verderbtheit, Diebstahl und Mord war so erstickend, dass wir uns gezwungen sahen, einige weitreichende Entscheidungen

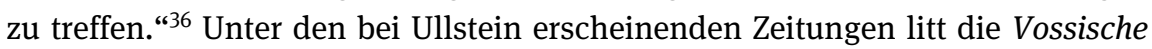
Zeitung wohl am stärksten unter den publizistischen Auswirkungen des Schriftleitergesetzes. Durch jene antisemitische Maßnahme sukzessive ihrer besten Federn und Stimmen beraubt, sank ihre Verkaufsauflage binnen 18 Monaten von 56.000 Exemplaren im Jahresschnitt 1932 auf knapp 37.000 Stück im Frühjahr 1934. Zudem hatte die Voss nie wirklich das Ausscheiden Georg Bernhards 1930 verkraftet: Unter dem im Gegensatz zu seinem Vorgänger eher vorsichtig agierenden Julius Elbau hatte sich die Zeitung der ohnehin im Reich vorherrschenden konservativen Grundstimmung angepasst und war zudem unpolitischer geworden. ${ }^{37}$

34 Vgl. Kempner, Hitler, S. 277.

35 Bis zu diesem Zeitpunkt hatte man beim Verlag die finanziellen Auswirkungen der verschiedenen NS-Boykottmaßnahmen noch kompensieren können, so Gustav Willner, der langjährige Chef der Buchhaltung des Verlags, im Jahr 1949: „In Bankverhandlungen, die ich mit dem damaligen Aufsichtsratsvorsitzenden, Dr. Ferdinand Bausback, führte, haben wir mit der Deutschen Bank und der Berliner Handelsgesellschaft Kreditabkommen über zusammen 4 Millionen Mark abgeschlossen, die nach unserer Auffassung durchaus genügten, die Firma trotz der durch die Nazi-Propaganda entstandenen und entstehenden Ausfälle durchzusteuern. “ In seiner anderen, bereits im Dezember 1945 abgegebenen eidesstattlichen Versicherung, ergänzte Willner an dieser Stelle bezüglich der Kredite: „Das muss auch der Parteileitung bekannt geworden sein, denn sie vergrößerte [nun] ihre Taktik gegen die Ullstein AG." Willners eidesstattliche Versicherungen vom 09.02.1949 und vom 01.12.1945, in: AS-UA, Bestand Ullstein, Band 17.

36 Nach Ullstein, Haus Ullstein, S. 244.

37 Siehe Klein, Georg Bernhard, S. 234. 
Das traditionsreiche Blatt aber erforderte, bei abnehmender Liquidität des Ullstein-Verlags, weiterhin einen jährlichen siebenstelligen Zuschuss. So entschloss man sich im Frühjahr 1934, Berlins älteste Zeitung einzustellen: Am 24. März verkündete man das Ende der Vossischen Zeitung zum 31. März 1934. ${ }^{38}$

Doch die Vossische Zeitung war nicht das einzige Blatt, das 1934 eingestellt werden musste: Im Oktober beendete man das Erscheinen des Uhu, eines Magazins „für breite Schichten“, das kurz zuvor noch in Monatshefte umgetauft worden war. Aber es gab auch Neugründungen im Jahr 1934: Im Februar gab Ullstein erstmals das Reichssportblatt als Organ des Reichssportführers heraus, dieser Publikation waren auch die Turnzeitung und die Sportjugend angeschlossen. ${ }^{39}$

Ebenfalls zum Jahresbeginn 1934 wurden der Berliner Illustrirten Zeitung die Kriegserinnerungen Hermann Görings als Fliegeroffizier, verfasst von zwei ehemaligen Kameraden, als mehrteilige Serie angeboten. ${ }^{40}$ Nach anfänglichem Widerstand willigte Ullstein in den Abdruck ein; die Korrekturabzüge mussten gleichwohl zur persönlichen Genehmigung dem Reichskommissar für Luftfahrt vorgelegt werden. Die Serie begann mit der Ausgabe Nr. 12 des 43. Jahrgangs am 25. März 1934 unter dem Titel: „Ein neuer großer Tatsachenbericht: Die Kriegserlebnisse des Fliegerleutnants Göring und seiner Freunde: Treue in der Luft“. Der zweite Teil der Serie wurde bereits nicht mehr publiziert, stattdessen druckte man den unwahren Hinweis, dass Göring Einwände gegen die von ihm selbst initiierte Serie geltend gemacht habe. ${ }^{41}$

Schon die erste Folge der Serie war mitten im Produktionsprozess gestoppt worden: Jene Ausgabe von 25. März war bereits seit dem 20. März „im Druck“, ein bei Illustrierten üblicher, langwieriger Prozess. Am 21. März, als zumindest

38 Auf der Titelseite dieser Ausgabe ließ der Ullstein-Verlag verlauten: „Die Aufgabe eines Blattes im Stil der Vossischen Zeitung ist nach unserer Ansicht beendet. So haben wir denn aus freien Stücken den schmerzlichen und folgerichtigen Entschluss gefasst, die Vossische Zeitung aufzugeben und sie nach dem Ende dieses Monats nicht mehr erscheinen zu lassen.“ Siehe auch teilweisen Nachdruck der dreiteiligen Serie über die Bedeutung der Voss, ursprünglich veröffentlicht an den letzten drei Erscheinungstagen, verfasst von: Heuss, Drei Jahrhunderte, S. 119-140.

39 Aus: Bericht über die Entwicklung der Kapitalbeteiligung und die Veränderung der Verlagsobjekte des Verlages Ullstein (seit 1938 Deutscher Verlag) von 1933-1945, verfasst von Gustav Willner am 25.07.1945, in: AS-UA, Bestand Ullstein, Band 4.

40 Schilderung nach Mendelssohn, Zeitungsstadt, S. $494 \mathrm{f}$.

41 Aus der BIZ, Nr. 13, 43. Jahrgang: „Die ,Berliner Illustrirte Zeitung hat in ihrer vorigen Ausgabe den Beginn einer Serie eines Mitarbeiters gebracht, die die Erlebnisse des Herrn Ministerpräsidenten und Reichsluftfahrtministers Göring im Krieg schildert. Die weitere Veröffentlichung dieser Serie ist von dem Herrn Ministerpräsidenten untersagt worden, da er Form und Art der Veröffentlichung missbilligt.“ 
die Teilauflagen für das Ausland und die Provinz nicht nur gedruckt, sondern bereits vom Vertrieb zugestellt worden waren, rief Joseph Goebbels persönlich aus dem Reichspropagandaministerium an und verbot den Weiterdruck der Berliner Illustrirten, da die neue Serie „unstatthaft“ sei; gerade der Druck in dem demokratisch gesinnten Ullstein-Verlag soll Goebbels aufgestoßen haben, ganz zu schweigen von der vielfach kolportierten Konkurrenz zwischen Göring und Goebbels - eine schmeichelhafte Titelgeschichte in der am weitesten verbreiteten Zeitschrift des Deutschen Reichs lag wohl nicht in der Interessensphäre des Propagandaministers.

Als Resultat dieser Intervention wurden bereits ausgelieferte Exemplare der Nummer 12 zurückgerufen oder beschlagnahmt. Im Rest der noch zu druckenden Auflage wurde das Göring-Thema ersetzt. Gleichwohl stellte dieser Eingriff in den Produktions- und Vertriebsverlauf eine massive Störung dar und resultierte in nicht unbeträchtlichen finanziellen Einbußen. ${ }^{42}$

Ein Ende April 1934 veröffentlichter Leitartikel der Grünen Post diente den Machthabern schließlich als Anlass, eine deutlich härtere bis existenzbedrohende Taktik gegen den Ullstein-Verlag anzuwenden. ${ }^{43}$ Vorausgegangen war diesem Artikel eine Rede, die Propagandaminister Goebbels am 19. April 1934 im Rahmen der „Führertagung des Reichverbandes der deutschen Presse“ im Plenarsaal des Preußischen Landtags gehalten hatte. ${ }^{44}$ In gewohnt abfällig sarkastischer Weise hatte der Minister sich über das Mitläufertum, die starke Anpassung an das NS-System in weiten Teilen der Presse geäußert. ${ }^{45}$ Eine Zeitung re-

42 Vgl. hierzu die nach dem Krieg aufgezeichneten eidesstattlichen Versicherungen von Gustav Willner vom 09.02.1942 (,Als die Propagandaaktion gegen den Verlag Ullstein keine Wirkung gezeigt hatte, begann die Partei mit stärkeren direkten Aktionen, indem sie zunächst im Frühjahr 1934 der Berliner Illustrirten Zeitung Schwierigkeiten machte...") und Fritz Ross vom 31.07.1951 („Am 25. März 1934 wurde durch Goebbels der Vertrieb der bereits gedruckten Berliner Illustrirten Zeitung - immer noch 1 1 1/2 Millionen Exemplare - wegen eines von Göring der Redaktion aufgezwungenen Tatsachenberichtes über ihn als Flieger verboten. Göring war gerade aus Berlin abwesend, und diese Gelegenheit hatte Goebbels sofort benutzt.“) Beide eidesstattlichen Erklärungen in: AS-UA, Bestand Ullstein, Band 17.

43 Siehe Koszyk, Deutsche Presse 1914-1945, S. 404 f.

44 Hierzu Mendelssohn, Presse gefesselt, S. $214 \mathrm{f}$.

45 Auszug aus der Rede: „Es ist zuviel verlangt, dass die Homere der Demokratie nun auch die Homere des Dritten Reiches werden. [...] Die Presse hat kein Gesicht mehr, nicht deshalb, weil man ihr das Gesicht genommen hätte, sondern weil die kein Gesicht haben, die sie schreiben! Wir haben heute die sonderbare Ehre, am meisten in den Blättern gelobt zu werden, die uns früher am meisten angetan haben. Wir verzichten aber darauf, und es wäre uns lieber, sie stünden in charaktervoller Reserve, so wie mir auch die viel lieber sind, die aus Charakter der Partei fernblieben, als die, die sofort die Situation ausnutzten und sich mit einem gewagten Sprung in die Partei hinüberretteten! Ich kann die Presse nicht mutiger machen, als sie ist. [...]“. Aus: Rede des Reichsministers Dr. Goebbels auf der Führertagung des Reichsverbandes 
agierte auf die Schmähung durch Goebbels. In der Grünen Post vom 29. April 1934 (Nummer 17/8. Jahrgang) erschien der Leitartikel: „Herr Reichsminister ein Wort bitte!“, verfasst vom Chefredakteur der Sonntagszeitung, Ehm Welk, unter dem Pseudonym Thomas Trimm ${ }^{46}$. In diesem offenen Brief wurde Goebbels aufgefordert, sich über die vermeintlichen Ursachen der von ihm öffentlich geschmähten Gleichförmigkeit in der deutschen Presselandschaft zu äußern.

Zudem holte Welk zum gezielten publizistischen Gegenschlag aus, indem er das von der NS-Presse hergestellte erfolglose Plagiat der Grünen Post, die Braune Post, angriff:

Wir gaben der Grünen Post als der ersten großen deutschen Sonntagszeitung einen bestimmten Inhalt, der sich im Kampf für den großdeutschen Gedanken, in Heimat- und Tierliebe, in der Pflege deutschen Brauchtums und deutscher Sitte kundtat. Wenn man heute die in so vielen deutschen Ländern die von uns gefundene Form des Blattes bis in die zufälligen Einzelheiten kopiert und den Inhalt zu kopieren versucht und so eine traurige Gleichförmigkeit auch noch der Sonntagszeitungen in Deutschland schafft - Herr Reichsminister, sollen wir nun wieder eine neue Form suchen?

In einer für diese Tage durchaus als mutig zu bezeichnenden Wortwahl setzte sich Welk in dem Leitartikel auch mit der Beschränkung der Pressefreiheit unter dem NS-Regime auseinander: „Sie sind, Herr Reichsminister, ein Freund des Witzes und der Ironie. Wer so arbeitet, wird nicht leicht gleichförmig. Unsere Grenzen sind da aber enger gezogen. Früher, da konnten wir zum Beispiel diese geistige Übung gelegentlich auch an behördlichen Maßnahmen und behördlichen Personen erproben - Herr Reichsminister, bei aller Aufforderung von Ihnen: ich weiß nicht recht.“

Der Propagandaminister empfand dies als offene Provokation seitens der Grünen Post und ließ die Ausgabe beschlagnahmen - und hatte somit endlich einen vermeintlich handfesten Anlass, um gegen Ullstein in größerem und deutlich schädlicherem Maße als bisher vorzugehen. Die Beschlagnahme der Ausgabe erfolgte erst nach dem Erscheinen der Gesamtauflage, nicht schon während des noch laufenden Produktions- und Vertriebsprozesses wie bei der Berliner Illustrirten mit den Göring-Memoiren. Dabei hatte die am Sonntag erscheinende Grüne Post eine mindestens genauso lange redaktionelle und tech-

der deutschen Presse am 19. April 1934, zitiert nach: Michaelis, Herbert u. Ernst Schraepler (Hrsg.): Ursachen und Folgen. Vom deutschen Zusammenbruch 1918 und 1945 bis zur staatlichen Neuordnung Deutschlands in der Gegenwart. Eine Urkunden- und Dokumentensammlung zur Zeitgeschichte, Bd. 9: Das Dritte Reich. Die Zertrümmerung des Parteienstaates und die Grundlegung der Diktatur. Berlin 1964, S. $438 \mathrm{f}$.

46 Zitiert nach Grüne Post vom 29.04.1934, S.1, abgedruckt bei Mendelssohn, Zeitungsstadt, S. $504 \mathrm{f}$. 
nische Anlaufphase wie die an Donnerstagen erscheinende BIZ. Dies lässt nur den Schluss zu, dass man den Ehm-Welk-Artikel als willkommene Provokation betrachtete und in den Produktionsprozess nicht einschritt, um ein Alibi-Argument gegen ein Verbot der Grünen Post zu haben. ${ }^{47}$

Der Ullstein-Verlag erhielt die ministerielle Anweisung, dem Chefredakteur sofort zu kündigen. Kurzzeitig wurde Ehm Welk daraufhin in das Konzentrationslager Oranienburg verbracht. Nach ausländischen Protesten wurde er nach acht Tagen wieder entlassen, erhielt aber vorübergehend Schreibverbot. ${ }^{48}$

Die weitreichendste Folge des Leitartikels war jedoch das dreimonatige Verbot der Grünen Post, eine Verbotsdauer, die selbst für damalige Verhältnisse erstaunlich lang war. 1933 hatte die Zeitschrift fast 500.000 Abonnenten und eine Auflage von 715.921 Exemplaren - ihr Verbot gefährdete somit die wirtschaftliche Existenz der Ullstein AG. ${ }^{49}$

Mit dem Verbot wurde eine Erklärung veröffentlicht, die diese Maßnahme als notwendig begründete, „um die Autorität der nationalsozialistischen Regierung zu wahren“. Der Ullstein-Verlag hätte die Pflicht gehabt, „durch zweckbewusste Personalpolitik...für die gesamte Haltung der Verlagserzeugnisse in ihrer Arbeit für den nationalsozialistischen Aufbau Sorge zu tragen. Der Verlag Ullstein ist dieser Aufgabe nicht nachgekommen, als er einen Mann wie Ehm Welk zum Schriftleiter ausgerechnet einer Landzeitung machte. “50

Das monatelange Verbot der auflagenstarken Sonntagszeitung führte zu erheblichen finanziellen Einbußen beim Verlag. ${ }^{51}$ Die Einschnitte stellten sich als so gravierend heraus, dass man von Ullstein-Seite beschloss, auf die Regierung zuzugehen, um eine Minderung der Verbotsdauer zu erreichen. Die Nationalsozialisten hatten der Familie ohnehin deutlich gemacht, dass sie mit Leib und Leben spielte, falls sie einem Verkauf nicht zustimmen würde. ${ }^{52}$

47 In sein Tagebuch notierte Goebbels am 30.04.1934: „,Grüne Post“ wird unverschämt gegen mich. Heute Verbot fällig. Ich werde diesen frechen Juden wieder mal zeigen, dass ich auch anders kann.“ Aus: Fröhlich, Elke (Hrsg.): Die Tagebücher von Joseph Goebbels. Teil I: Aufzeichnungen 1923-1941. Band 3/I April 1934-Februar 1936. München 2005, S. 41.

48 Koszyk, Deutsche Presse 1914-1945, S. 404, weist daraufhin, dass Ehm Welk später Redakteur bei der in Stettin erscheinenden NS-Kulturzeitschrift Das Bollwerk wurde.

49 Wippermann, Wolfgang: Eule und Hakenkreuz. Ullstein und Deutscher Verlag im „Dritten Reich“ 1933 bis 1945. In: Ullstein Chronik 1903-2011. Hrsg. von Anne Enderlein. Berlin 2011. S. 198-219, hier S. 205.

50 Auszüge der Erklärung bei: Dussel, Konrad: Deutsche Tagespresse im 19. und 20. Jahrhundert. Münster 2004 (Einführungen - Kommunikationswissenschaft 1), S. 167.

51 Siehe Lindner, Arisierung, S. 77.

52 Aus einem Brief von Rudolf Ullstein an das „Denacifierungsgericht in München“ vom 17.12.1948 anlässlich des Amann-Prozesses: „Der Hauptdruck aber setzte ein bei und vor den Verkaufsverhandlungen. Wir konnten hören - es wurde uns nicht mit dürren Worten gesagt - 
Der Klageantrag bei der 42. Zivilkammer (Wiedergutmachungskammer) des Landgerichts Berlin vom 9. August 1951 versammelt einige aufschlussreiche Aussagen über die Ereignisse des Jahres 1934 aus Sicht der Ullsteins. ${ }^{53}$ Die hier wiedergegebenen Vorkommnisse beginnen mit dem Boykottaufrufen für Ullstein-Produkte bereits zum Ende der 1920er Jahre durch Parteiorgane der NSDAP. Diese Aktivitäten und natürlich die Weltwirtschaftskrise werden für den massiven Rückgang der Reingewinne der Ullstein AG seit 1929 geltend gemacht. Neben den bereits geschilderten Verhaftungen von Familienmitgliedern werden auch die Verbote einiger Ullstein-Presseerzeugnisse in den Aussagen thematisiert.

Die eidesstattliche Versicherung von Fritz Ross, der seit dem Frühjahr 1933 als „arischer“ Schwiegersohn Hans Ullsteins dessen Position als stellvertretender Aufsichtsratsvorsitzender des Verlags übernommen hatte, wurde wenige Tage vor dem Klageantrag des Jahres 1951 verfasst. ${ }^{54}$ Ross erwähnt, dass er es geschafft hatte, die Verbote der Berliner Illustrirten Zeitung (vom 25. März 1934) und der Grünen Post (29. April 1934) wieder aufheben zu lassen: „Die Freigabe dieser Zeitung erfolgte erst, nachdem ich am 7. Juni 1934 als Bevollmächtigter der Familie Ullstein meine Paraphe unter den ,freiwilligen` Kaufvertrag gesetzt hatte. " 55

Nach dem Verbot der Grünen Post hatten sich die Ereignisse deutlich zugespitzt. Ross trat über die Familie Haushofer, die seit gut einem Jahr wie andere Bekannte der Verlegerfamilie im Besitz von Ullstein-Aktien war (siehe Kapitel 3.1), an Hitlers Stellvertreter, Rudolf Heß, heran. Die Ullsteins wollten auf diese Weise wohl Goebbels übergehen und erhofften sich von Heß eine Übereinkunft bezüglich der Grünen Post. Dieser zeigte sich bei dem kurzen Treffen Anfang Mai 1934 kompromisslos, wie sich Fritz Ross erinnerte:

Heß erklärte eiskalt, es sei nicht verständlich, wieso die Familie Ullstein die Zeichen der Zeit nicht mehr verstünde. An ihrem Verbleiben im Verlage sei nicht zu denken. Im Gegenteil, wenn die Familie Ullstein nicht bald aus dem Ullsteinhaus verschwinden würde,

dass Herr Goebbels schon Mittel und Wege finden würde, um den Verlag zum Schweigen zu bringen oder gänzlich zu ruinieren. Wir Brüder und unsere im Verlag arbeitenden Nachkommen wurden mit dem Konzentrationslager bedroht, wenn wir nicht verkauften.“ Brief Rudolf Ullsteins in: AS-UA, Bestand Ullstein, Band 16.

53 Klageantrag unter dem Aktenzeichen 42.WGK. 461/51, eingereicht von Ludwig Ruge am 09.08.1951, bei der 42. Wiedergutmachungskammer am Landgericht Berlin, in: AS-UA, Bestand Ullstein, Band 17.

54 Eidesstattliche Versicherung von Fritz Ross vom 31.07.1951, in: AS-UA, Bestand Ullstein, Band 17.

55 Eidesstattliche Versicherung von Fritz Ross vom 31.07.1951, in: AS-UA, Bestand Ullstein, Band 17. 
so würde die Partei zu anderen Maßnahmen greifen, worunter er zweifellos die Verschleppung ins KZ-Lager verstand. Ich berichtete sofort nach meiner Rückkehr aus der Hedemannstraße in der Kochstraße den Brüdern Ullstein über meine Unterredung mit Rudolf Heß, die uns keine Hoffnung ließ. ${ }^{56}$

Bereits im Jahr 1949 hatte der Rechtsanwalt Ludwig Ruge, ein Freund der Familie Ullstein und renommierter Berliner Anwalt, eine eidesstattliche Versicherung über die Umstände der Zwangsveräußerung vorgelegt, demnach drohte man der Ullstein AG nach dem Verbot der Grünen Post auch mit der Zwangseinstellung der Berliner Morgenpost: „Dr. [Franz, d. Verf.] Ullstein erklärte mir, dass nach den ihm zugegangenen Nachrichten kein Zweifel darüber bestehen könne, dass man das Unternehmen vollkommen ruinieren werde, wenn die Familie es nicht abgeben sollte, so dass die beteiligten Familienmitglieder sich entschlossen hätten, dem Druck zu weichen und ihre Beteiligungen zu veräuBern. “57

Die Ullsteins sahen sich also gezwungen in Verkaufsverhandlungen einzutreten. Ihnen war klar geworden, dass ein weiteres Verbleiben in ihrem Verlag nicht nur den eigenen Untergang, sondern auch das Ende des Unternehmens samt seiner nahezu 10.000 Arbeiter und Angestellten bedeutet hätte - zumal man den Verlegern bereits erneut drohte, neben der Grünen Post weitere Zeitungen verbieten zu lassen. ${ }^{58}$

Franz Ullstein hatte über Hermann Dietrich, den Reichsfinanzminister des Kabinetts Brüning, die Bekanntschaft mit dem Wirtschaftsberater Dr. Max Winkler gemacht; die Familie beauftragte nun ihren langjährigen Freund und Rechtsberater Dr. Ludwig Ruge, in ihrem Namen unverzüglich in Verhandlungen mit Winkler zu treten. Dieser sollte schnellstmöglich einen Käufer für das Familienunternehmen finden. Denn jede weitere Verzögerung hätte nur das Verbot weiterer Verlagserzeugnisse und damit eine zusätzliche Wertminderung des Verlags zur Folge gehabt.

Max Winkler war 1919 für die DDP in die Preußische Landesversammlung gewählt worden, wo er sich vor allem für die Erhaltung des Deutschtums im Osten engagierte. Für diesen Zweck gründete er mehrere Gesellschaften, um jene

56 Eidesstattliche Versicherung von Fritz Ross vom 31.07.1951, in: AS-UA, Bestand Ullstein, Band 17. Eine Ullstein-Delegation war am 11.05.1934 auch bei Goebbels vorstellig geworden. Dieser notierte in sein Tagebuch: „Die Herren von Ullstein. Ich habe ihnen sehr derb die Meinung gesagt. Von Juden und so. Verbot der ,Grünen Post“ wird nicht aufgehoben. Sollen erst Juden eliminieren.“ Aus Fröhlich, Tagebücher, Band 3/I April 1934-Februar 1936, S. 46.

57 Eidesstattliche Versicherung von Ludwig Ruge, datiert auf den 08.02.1949, als Anhang der Klageschrift, in: AS-UA, Bestand Ullstein, Band 17.

58 Vgl. hierzu auch eidesstattliche Erklärung von Gustav Willner vom 09.02.1949, in: AS-UA, Bestand Ullstein, Band 17. 
deutschen Zeitungen zu unterstützen, die in den durch den Versailler Vertrag verlorenen gegangenen deutschen Gebieten oder Landstrichen mit deutschen Minderheiten herausgegeben wurden; die wichtigste dieser Gesellschaften war die Cautio Treuhandgesellschaft mbH.

Während der Weimarer Republik war Winkler mit seinen Unternehmungen bei immer mehr Zeitungen präsent, von der Saarbrücker Zeitung über das Memeler Dampfboot bis zur Rigaschen Rundschau. 1933 konnte Dr. h.c. Winkler sich damit brüsten, für sämtliche Reichsregierungen Weimars tätig gewesen zu sein; zu dieser Zeit verwaltete er als Treuhänder des Reichsbesitzes an Zeitungsverlagen insgesamt 19 Unternehmungen.

Im Auftrag der Reichsregierung verschmolz Max Winkler die Nachrichtenagenturen T.U. und WTB zum Deutschen Nachrichtenbüro. Neben seiner Tätigkeit als Wirtschaftsberater der abgetretenen Ostprovinzen sowie für die Grenzlandpresse fungierte Winkler später als Beauftragter für die Gleichschaltung der Presse. Ab 1939 war er Leiter der Haupttreuhandstelle Ost und somit „Reichstreuhänder“..$^{59}$

Gemäß der Aussage Winklers als Zeuge bei den Nürnberger Prozessen ${ }^{60}$ trat Max Amann Ende Januar oder Anfang Februar 1934 an ihn in der Causa Ullstein heran. ${ }^{61}$ Amann war seit 1922 Direktor des Franz Eher Verlags und seit 1933 der Präsident der neu gegründeten Reichspressekammer. Ihm oblag die „Gleichschaltung der Presse“ - oder die Vernichtung missliebiger Publikationen. Winkler behauptete in seiner Aussage, dass er es war, der Amann und Goebbels den Vorschlag unterbreitete, die Ullstein AG zu erwerben anstatt zu zerschlagen.

$\mathrm{Zu}$ diesem Zeitpunkt, auch das erklärte Winkler in seiner Aussage, haben die Ullsteins noch nichts von den Plänen Amanns und Goebbels' gewusst:

59 Zusammenfassung des Lebenslaufs nach: Wermuth, Helga: Dr. h.c. Winkler. Ein Gehilfe staatlicher Pressepolitik in der Weimarer Republik. Dissertation. München 1975. Sowie: Lerg, Winfried B.: Max Winkler, der Finanztechniker der Gleichschaltung. In: ZV+ZV 13 (1963). S. 610-612; Schmidt, Fritz: Presse in Fesseln. Eine Schilderung des NS-Pressetrusts. Berlin 1947, S. 43-45.

60 Winkler sagte am 10.09.1947 bei den Vernehmungen, die dem Wilhelmstraßenprozess vorangingen, aus. Laut Robert W. Kempner, der Winkler persönlich befragte, hätte Winkler als Zeuge gegen den später wegen Verbrechens gegen die Menschlichkeit zu sieben Jahren Haft verurteilten ehemaligen Reichspressechef Otto Dietrich in Betracht kommen können. Vgl. Kempner, Hitler, S. 278.

61 In seiner Vernehmung behauptet Winkler, dass er sich wegen der Ullstein-Entziehung im Februar 1934 mit Amann und Goebbels getroffen habe. Wahrscheinlicher ist jedoch aufgrund des zeitlichen Ablaufs eher ein Zusammenkommen zum Jahresbeginn 1934, also deutlich vor dem finanziell verheerenden Verbot der Grünen Post. 
Im Laufe der Unterhaltung habe ich dann die Bemerkung gemacht, dass man statt zu vernichten, an einen Erwerb denken könnte. Goebbels stellte die Frage, ob ich das für möglich halte, worauf ich antwortete, dass es auf einen Versuch ankäme. G. beendete das Gespräch mit der Erklärung, er werde Vortrag halten und darauf zurückkommen. [...] Goebbels ließ mich am Tag nach der Unterhaltung [...] kommen und teilte mir mit, dass er ermächtigt sei, mich zu beauftragen, Ankaufsverhandlungen über die Ullstein AG zu führen. ${ }^{62}$

Der Ullstein-Verhandlungsführer Dr. Ludwig Ruge traf sich am 17. Mai 1934 erstmals mit Max Winkler. Neben Ruge nahmen vom Aufsichtsrat des Verlags noch Fritz Ross und Ferdinand Bausback teil. Im Zuge der Verhandlungen erklärte Winkler, dass er lediglich als Treuhänder fungiere und nicht befugt sei, seinen Auftraggeber zu nennen. ${ }^{63}$

Zudem stellte er klar, dass es ihm lediglich erlaubt sei den Nennwert der Aktien, also 6 Mio. RM, zu bezahlen. Fritz Ross erinnert sich:

Von ihm [Winkler, d. Verf.] habe ich dann erfahren, dass das Spiel der Nazis berechnet war. Nach dem Verbot der Grünen Post, das von den Nazis auch als Todesstoß des Ullsteinhauses gedacht war, wurde Winkler von Goebbels bevollmächtigt, Verkaufsverhandlungen mit Ullstein zu führen [...] Es war von vornherein deutlich, dass Dr. Winkler ein limitierter Preis vorgeschrieben war, über den er nicht hinausgehen durfte. Die Versuche, einen auch nur angemessenen Preis zu erhalten, waren daher zum Scheitern verurteilt, obwohl Winkler als Fachmann genau wußte, dass der Wert des Ullstein-Verlages ein Vielfaches des Kaufpreises war und mit mindestens 60 Millionen Goldmark geschätzt werden konnte. ${ }^{64}$

Wie kam Fritz Ross auf diesen Wert? Gustav Willner, der seit 1921 als Leiter des gesamten Buchhaltungswesens der Ullstein AG (und später des „Deutschen Verlags“) fungierte, fasste in einer eidesstattlichen Aussage zusammen: ${ }^{65}$

Die Gewinnbeteiligung der leitenden Angestellten (Direktoren, Prokuristen, Abteilungsleiter) betrug für die Geschäftsjahre 1927-1930 je 25\%, 1931 20\%, errechnet von einem fiktiven Aktienblock. Wenn man als durchschnittliche Effektiv-Verzinsung der bedeutenden deutschen Aktiengesellschaften 5\% rechnet, so ergibt die durchschnittliche Dividende von 25\% für das Aktienkapital einen Kurs von 500. Da das eigentliche Kapital der Ullstein AG 12 Millionen betrug, ergibt das einen Kapitalwert von 60 Millionen. Mit 60 Millionen

62 Schriftliche Erklärung Max Winklers vom 12.09.1947, Institut für Zeitgeschichte (IfZ), Archiv, ZS 517, Bl. 50-55, hier Bl. 53.

63 Schilderung u. a. bei Mendelssohn, Zeitungsstadt, S. $512 \mathrm{f}$.

64 Eidesstattliche Versicherung von Fritz Ross vom 31.07.1951, in: AS-UA, Bestand Ullstein, Band 17.

65 Aussage von Gustav Willner vom 09.02.1949, in: AS-UA, Bestand Ullstein, Band 17. 
wurde in den Jahren vor der Machtübernahme durch die Nazis die Ullstein AG allgemein bewertet. ${ }^{66}$

Ein schriftlicher Vertrag wurde auf Wunsch Winklers nicht geschlossen - es wurde lediglich ein im Entwurf vorliegender Vertrag durch Winkler, Ross und Ruge paraphiert. Am 7. Juni 1934 erhielt Ludwig Ruge einen Brief von Winkler, in dem den Ullsteins eine Frist bis $18 \mathrm{Uhr}$ am gleichen Tage gegeben wurde, um den Verkauf zu unterzeichnen. Dazu Fritz Ross: „Es war nach Winklers Äußerung kein Zweifel, dass es sich um ein Ultimatum handle, dessen Nichtannahme uns, d.h. die Familie, ins KZ gebracht hätte. Nachher habe ich durch einen Freund erfahren, dass ich den 30. Juni 1934 nicht überlebt hätte, wenn ich noch aktives Aufsichtsratsmitglied der Ullstein AG gewesen wäre.“67 Die Ullsteins unterzeichneten. Am 10. Juni 1934 schieden Franz, Hermann, Rudolf und Karl Ullstein aus der Ullstein AG aus.

Für die Aktien des Verlags zahlte man, wie von Käuferseite beabsichtigt, 6 Mio. RM. Die nicht stimmberechtigten Aktien (Genussscheine) wurden für 4 Mio. RM veräußert, wobei diese in verzinsliche Schuldverschreibungen umgewandelt werden sollten. Der Pensionskasse des Verlags wurden 400.000 RM gutgeschrieben. Die beim Verlag liegenden Gründerrechte wurden pauschal mit 2 Mio. RM abgefunden, allerdings rechnete man hier noch die Abfindung in Höhe von 1,5 Mio. RM für die Gründerrechte an der (eingestellten) Vossischen Zeitung gegen, die an die Lessingsche Erbengemeinschaft gezahlt werden sollte.

Als Käuferin des Verlags fungierte Winklers Cautio GmbH. In ihren Besitz ging das Verlagshaus zum 30. Juni 1934 über - die Aktien wurden für sie bei der Deutschen Bank hinterlegt. Zunächst blieb unbekannt, in wessen Namen die Cautio GmbH die Ullstein-Transaktion durchgeführt hatte. Doch der Auftraggeber war niemand anderes als die NSDAP, die die Ullstein AG auf diese Weise dem Parteiverlag Franz Eher übertrug und somit das Pressemonopol deutlich ausbaute.

66 Dass die finanzielle Lage zur Zeit des Zwangsverkaufs 1934 nicht so trostlos war, wie die Nationalsozialisten und ihr Handlanger Winkler schilderten, zeigen auch die Zahlen, die Heinz Ullstein im Zuge der Nürnberger Prozesse an Robert Kempner als Erwiderung an die Aussagen Winklers schickte: „Trotz der Anfeindungen, denen der Verlag damals aus politischen Gründen ausgesetzt gewesen ist, war die wirtschaftliche Lage ausgezeichnet. Schließlich haben „Illustrierte“ [die Berliner Illustrirte Zeitung, d. Verf.] und „Morgenpost“ [Berliner Morgenpost, d. Verf.] zusammen immer noch einen Gewinn von 15 Millionen Mark erbracht. Demgegenüber spielte selbst eine Unterbilanz von 1,5 Millionen Mark, wie sie die „Vossische Zeitung“ aufwies, keine Rolle.“ Brief an Kempner vom 21.10.1947, aus: AS-UA, Bestand Ullstein, Band 16. 67 Eidesstattliche Versicherung von Fritz Ross vom 31.07.1951, in: AS-UA, Bestand Ullstein, Band 17. 
Der Eher-Verlag selbst hatte nicht über die Finanzmittel zum Ankauf verfügt, doch der Parteiverlag hatte bei der Bank der Deutschen Arbeit einen Kredit über 26 Mio. RM aufnehmen dürfen - und mit dieser Summe wurden Ankäufe wie der des Ullsteins-Verlags und anderer politisch unliebsamer Pressehäuser finanziert.

Ein beliebtes Argument gegen die Restitution des Ullstein-Verlags lautete, dass der Verlag sich zum Zeitpunkt des Verkaufs in so großen Schwierigkeiten befunden hätte, dass die Ullsteins ohnehin hätten verkaufen müssen. Tatsächlich aber waren 1934 die Folgen der Wirtschaftskrise bereits spürbar abgemildert worden - kein Wunder also, dass die NS-Regierung zu Zeitungs-Verboten greifen musste, um die Ullsteins zum Zwangsverkauf zu drängen.

Was hieß das in Zahlen? Neben den jährlichen Pauschalvergütungen von 500.000 RM pro Jahr und den ebenfalls jährlichen Gründervergütungen von 500.000 RM, die der Familie vornweg gutgeschrieben wurden, ergab die Jahresbilanz für 1929 einen Gewinn über 1.339.000 RM. Im Jahr 1930 sank der Gewinn auf 1.151.300 RM und 1931 auf 629.000 RM. Im Jahr 1932 verbuchte die Ullstein AG erstmals einen Verlust (über 14.160 RM).

Die Bilanz für das Jahr 1933 hatte bei einer Gutschrift für die Familie Ullstein über 625.000 RM (davon 125.000 RM Spesenpauschale für das 1. Quartal 1933 und die 500.000 RM für die jährliche Vergütung der Gründerrechte) noch einen Verlust von 619.000 RM verzeichnet - doch bereits für 1934 konnte wieder ein Gewinn, nämlich über 530.000 RM, verbucht werden (allerdings ohne die in den früheren Jahren verbuchten Spesen und Gründerrechte). Schließlich belief sich der Gewinn im Jahr 1935 auf 548.000 RM, zudem wurden 960.000 RM als Sonderabschreibung auf den Grundbesitz verbucht, der nach dem neuen Einheitswert ermittelt wurde. ${ }^{68}$ Das Jahr 1936 schloss mit einem Gewinn von 190.235 RM, bei einer weiteren Sonderabschreibung auf den Grundbesitz in Höhe von 1.090.000 RM.

Nachfolgend stieg der Gewinn deutlich an, so dass der noch 1927 von der Familie Ullstein begründete Pensionsfonds bis 1943 auf 16 Mio. RM angeschwollen war (davon 14 Mio. RM in Reichsschatzanweisungen und 2 Mio. RM in Reichsschuldbucheintragungen). Als Sicherung für langfristige Verpflichtungen schuf der Verlag bei der Deutschen Bank ein Effekten-Depot, das sich bis 1945 auf 6.114.101,55 RM summierte. ${ }^{69}$

68 Zum 01.01.1935 wurde in Deutschland jedes Grundstück mit einem Einheitswert eingestuft. Dieser Wert gibt nicht den Kauf- bzw. Verkaufspreis wieder, sondern ist lediglich eine Bewertungsgrundlage zur Berechnung der Steuern.

69 Alle Angaben nach der Aufstellung ,Wie der Aktienbesitz der Familie Ullstein an den Parteiverlag überging“ des Verlags-Buchhalters Gustav Willner, datiert auf den 02.08.1945, in: ASUA, Bestand Ullstein, Band 4. 


\subsection{Der Ullstein-Verlag als Propagandainstrument (1934-1945)}

Was war zu diesem Zeitpunkt aus den fünf Söhnen des Verlagsgründers Leopold Ullstein geworden? Louis Ferdinand war bereits 1933 verstorben. Hans Ullstein starb 1935, ein Jahr nach dem Zwangsverkauf, im Alter von 76 Jahren. Die verbliebenen drei Brüder zogen sich in ihre Privathäuser zurück - fragte man sie, wem denn nun ihr früherer Verlag gehörte, antworteten sie stets, dass sie es selbst nicht wüssten. ${ }^{70}$ Dr. Franz Ullstein emigrierte, inzwischen 70 Jahre alt, zum Jahresende 1938 nach New York. Die Brüder Hermann (1875-1943) und Rudolf Ullstein (1874-1964) durften 1939 aus Deutschland ausreisen.

Es wird nicht bezweifelt, dass die drei Brüder quasi mittellos in Großbritannien und in den USA eintrafen. So musste Rudolf Ullstein als Vorarbeiter in einer Metallfabrik arbeiten, bevor er in einem britischen Verlag Anstellung fand. Durch die Emigration und die damit verbundenen Zwangsabgaben dürfte nahezu der gesamte Verkaufserlös verloren gegangen sein. ${ }^{71}$

Hermann Ullstein schildert in seinem Buch Das Haus Ullstein eindringlich die Methoden der Berliner Finanzbehörden, wenn es um die Ausplünderung der Emigranten ging. ${ }^{72}$ Er erinnert sich: „Meine Frau und ich hatten seit Monaten die Ausreise vorbereitet. Aber es war nicht so einfach. Die Steuerbehörde hatte tausend Fragen an uns zu stellen.“ Obwohl er bereits die „Reichsfluchtsteuer“ und die „Judenvermögensabgabe“ gezahlt hatte, enthielt man ihm seinen Pass vor. Erst gegen Zahlung der sogenannten „Helldorff-Spende“ an den Berliner Polizeipräsidenten, einer Zwangsabgabe speziell für die vermögenden Juden der Hauptstadt, über 100.000 RM bekamen er und seine Gattin ihre Papiere. $^{73}$

Im Berliner Landesarchiv befinden sich in den Unterlagen der Wiedergutmachungsämter Fotokopien vereinzelter Karteikarten, die einen groben Überblick über das im Zuge der Emigration eingezogene Vermögen der Familie Ullstein erlauben. ${ }^{74}$ Für den 1943 verarmt in New York verstorbenen Hermann Ullstein sind beispielsweise die Einrichtungsgegenstände aus seinem Haus in Berlin-Grunewald, Taunusstr. 7, aufgeführt: Kunstwerke und Einrichtungsge-

70 Mendelssohn, Zeitungsstadt, S. 515.

71 Münzel/Steiner, Der lange Schatten, S. 297.

72 Ullstein, Haus Ullstein, S. $278 \mathrm{f}$.

73 „Ein Problem war, dass der Rest meines Vermögens in Staatsanleihen angelegt war. Und da es Juden nicht erlaubt war, ihre Anleihen zu verkaufen, bekam ich dafür kein Bargeld. Es dauerte noch einen ganzen Monat, bevor auch diese Schwierigkeit überwunden war. Dann endlich erhielten wir unsere Pässe.“ Aus Hermann Ullstein, Haus Ullstein, S. 281.

74 Siehe hierzu: LAB-B Rep. 025-02, Nr. 2 (2 WGA 1242/50). 
genstände, Bronzefiguren der Berliner Bildhauerin Renée Sintenis, Täfelungen und vieles mehr.

Karl Ullstein (1893-1964), ein Sohn von Hans Ullstein, der in die USA emigriert war, forderte seine Judenvermögensabgabe über 161.200 RM sowie die von ihm geleistete Reichsfluchtsteuer über 176.657 RM zurück. Martha Ullstein, die Witwe des 1933 verstorbenen Louis Ullstein, beanspruchte laut der Akten des Wiedergutmachungsamtes die Rückzahlung der an das Finanzamt BerlinWilmersdorf Süd geleisteten Judenvermögensabgabe über 205.000 RM sowie der Reichsfluchtsteuer über 265.000,- RM. Zudem hatte sie bei ihrer Emigration eine Helldorff-Spende über 80.000 RM zahlen müssen. Hinzu kam eine Ausfuhrförderabgabe über 20.000 RM, die Martha Ullstein für „die Erlaubnis zur Mitnahme v. Umzugsgut“ an die Deutsche Golddiskontbank geleistet hatte.

Die liberale, demokratisch gesinnte Familie Ullstein und ihr beeindruckendes Presse-Imperium gehörten seit den Jahren der Weimarer Republik zum Feindbild der nationalsozialistischen Bewegung. Mit der Machtübernahme der Nationalsozialisten nutzten diese alle Druckmittel ihrer Diktatur, um die Ullstein AG zu schädigen und die Familie Ullstein $\mathrm{zu}$ bedrohen, auszuplündern und schließlich aus Deutschland zu vertreiben.

Den frühen Boykottaufrufen durch die Feinde der Republik und den Folgen der Wirtschaftskrise Anfang der 1930er Jahre konnte sich das Haus Ullstein noch erfolgreich entgegenstellen - zu beliebt waren seine Produkte, zu viel Renommee hatte sein Name. Doch mit den willkürlichen Zeitungsverboten, vor allem dem Verbot der umsatzstarken Grünen Post, gab man der Verleger-Familie einen Vorgeschmack auf den wirtschaftlichen Ruin, in den die Machthaber dieses publizistische Bollwerk bugsieren konnten. ${ }^{75}$ Also gaben die Ullsteins nach und veräußerten ihren Verlag weit unter Wert.

Dass einige Familienmitglieder mit ihrer Emigration bis zu den Exzessen der Pogromnacht 1938 warteten unterstreicht, dass sie noch immer die Hoffnung hegten, dass der NS-Spuk vergehen und sie ihren Verlag irgendwie zurückbekommen könnten. Nur ein Ullstein harrte unter permanenter Lebensgefahr während des Zweiten Weltkriegs in Berlin aus: Louis' Sohn Heinz Ullstein (1893-1969) war mit der „Arierin“ Änne Gettke verheiratet, was es ihm ermöglichte, zumindest geduldet zu sein. Er verdingte sich u.a. als Hilfsarbeiter bei der Reichsbahn.

Die NS-Führung war sich der Wirkung des Namens Ullstein natürlich bewusst, so ließ man zunächst davon ab, den Verlag umzubenennen. Die Leser, Inserenten und Abonnenten sollten über die neuen Besitzverhältnisse im Unklaren gelassen werden. Erst am 15. November 1937 wurde die Ullstein AG in

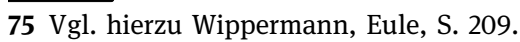


Deutscher Verlag umfirmiert und am 1. Januar 1938 in eine KG umgewandelt, als persönlich haftende Gesellschafter fungierten Max Winkler und Ferdinand Bausback mit je 10.000 RM, als einzige Kommanditistin die Cautio GmbH mit 11.980.000 RM. ${ }^{76}$ Über den Knorr \& Hirth Verlag und die Herold Verlagsanstalt wurde schließlich 1941 die Franz Eher Nachf. GmbH auch nominell Eigentümerin des Verlags. ${ }^{77}$

Am 11. Juli 1944 wurde die letzte Veränderung der Besitzverhältnisse während der NS-Zeit im Handelsregister vermerkt, denn an diesem Tag übertrug Knorr \& Hirth seine Anteile in Höhe von 980.000 RM ebenfalls an die Franz Eher Nachf. GmbH. Aufgrund dieser Maßnahme ging der Deutsche Verlag komplett in den Besitz des Parteiverlags der Nationalsozialisten über. $\mathrm{Zu}$ diesem Zweitpunkt überwies der Deutsche Verlag jeden Monat Millionenbeträge an die Franz Eher Nachf. GmbH - allein zwischen der Jahresmitte 1944 bis kurz vor Kriegsende summierten sich diese Zahlungen auf etwa 31 Mio. RM. ${ }^{78}$

Zum neuen Verlagsdirektor war 1934 Max Wießner (1885-1945) berufen worden, ein ehemaliger Redakteur der Frankfurter Zeitung und des Hamburger Fremdenblatts, der sich dort später zum Geschäftsführer hochgearbeitet hatte. Er war der Verfasser eines Gutachtens über den Ullstein-Verlag für Max Winkler, das dieser in den Verhandlungen rund um den Zwangsverkauf genutzt hatte.

Die traditionsreichen Ullstein-Zeitungen wurden „gleichgeschaltet“ und neue Zeitschriften wurden gegründet, umbenannt oder bestehende Publikationen in den Verlag integriert. Mit Kriegsbeginn arbeitete der Verlag eng mit der Kriegspropaganda des Regimes zusammen. ${ }^{79}$

Die marktbeherrschende Stellung des Verlags im Segment der Zeitschriften/ Illustrierten war während des Krieges noch gewachsen - wie David Oels ausführte, überstieg die Gesamtauflage der Zeitungen und Zeitschriften im Jahr 1940 zum ersten Mal in der Geschichte des Verlages die Marke von 10 Mio. Exemplaren; 1942 und 1943 waren es sogar über 12 Mio. Dies spiegelte sich in den

76 Siehe Mendelssohn, Zeitungsstadt, S. 532.

77 Nach Wippermann, Eule, S. 212.

78 Siehe Aufstellung von Gustav Willner „Wie der Aktienbesitz der Familie Ullstein an den Parteiverlag überging“ vom 02.08.1945, in: AS-UA, Bestand Ullstein, Band 4.

79 Vgl.: Holzer, Anton: Nachrichten und Sensationen. Die Berliner Illustrirte Zeitung und der deutsche Fotojournalismus vor 1936. In: Die Erfindung der Pressefotografie. Aus der Sammlung Ullstein 1894-1945. Begleitkatalog zur Ausstellung im Deutschen Historischen Museum, Berlin, vom 23. Juni bis 31. Oktober 2017. Hrsg. von Stiftung Deutsches Historisches Museum u. Axel Springer Syndication GmbH. Berlin 2017. S. 26-37, hier S. 36. 
Beschäftigungszahlen wider, im Februar 1941 befanden sich 13.292 Arbeitnehmer auf den Gehaltslisten des Deutschen Verlags. ${ }^{80}$

Hier eine Gesamtübersicht über die Veränderungen bei den Zeitungen und Zeitschriften von Januar 1933 bis Mai 1945: ${ }^{81}$

\section{3}

Einstellungen/Verkäufe: Tempo und Querschnitt

Neugründung: Die Sirene

1934

Einstellungen: Vossische Zeitung und Uhu (bzw. Monatshefte)

Neugründung: Reichssportblatt (darin angeschlossen: Turnzeitung und Sportjugend)

1935

Keine Veränderungen bei den Zeitungen/Zeitschriften.

1936

Neugründungen: Deutschland (eine Propaganda-Bilderzeitschrift), Hier Berlin (Rundfunkzeitschrift)

Ankauf: Das 12-Uhr-Blatt (Boulevard)

1937

Ankauf: Braune Post

Umbenennung: Aus der Modezeitschrift Bazar wurde die Neue Modenwelt

1938

Neugründungen: Der Stern (Filmzeitschrift)

1939

Ankauf: Deutsche Allgemeine Zeitung, Berliner Volks-Zeitung (aus dem ehemaligen Mosse-Verlag)

Zusammenlegungen (zum Teil mit verlagsfremden Objekten): Berliner Tageblatt und Germania (bisher Organ der Zentrums-Partei) wurden in die neu erworbene Deutsche Allgemeine Zeitung integriert. Die Rundfunkzeitschrift Sieben Tage wird in Hier Berlin integriert.

Umbenennung: Der Stern wurde in Erika unbenannt.

1940

Neugründungen: Das Reich sowie die Auslandszeitschrift Signal (speziell für die Auslandspropaganda der Wehrmacht konzipierter Ableger der Berliner Illustrirten Zeitung. Diese Zeitschrift wurde in bis zu 25 Sprachen übersetzt. Nicht zuletzt für die Herstellung dieser Publikation war der Einsatz von fremdsprachigen Zwangsarbeitern notwendig).

80 Zur betriebswirtschaftlichen Auswertung des Verlags siehe Oels, David: Die Monatsberichte Max Wießners an den Zentralparteiverlag der NSDAP Franz Eher Nachf. über wichtige Geschäftsvorfälle im Deutschen Verlag 1940-1945. Teil I: 1940-1941. In: Archiv für Geschichte des Buchwesens 69 (2014). S. 153-234, hier S. 155; sowie Oels, David: Die Monatsberichte Max Wießners an den Zentralparteiverlag der NSDAP Franz Eher Nachf. über wichtige Geschäftsvorfälle im Deutschen Verlag 1940-1945. Teil II: 1942-1945. In: Archiv für Geschichte des Buchwesens 70 (2015). S. 107-240.

81 Siehe „Bericht über die Entwicklung der Kapitalbeteiligung und die Veränderung der Verlagsobjekte des Verlages Ullstein (seit 1938 Deutscher Verlag) von 1933-1945“, verfasst von Gustav Willner am 25.07.1945, in: AS-UA, Bestand Ullstein, Band 4. 
1941

Einstellungen: Braune Post, Hier Berlin

1942

Neugründung: Europäische Literatur

1943

Neugründung: Deutsche Romanpost ${ }^{82}$

Einstellungen: Berliner Allgemeine Zeitung, BZ am Mittag, Erika, Die Dame, Bauwelt-Musterschau

1944

Einstellungen: Europäische Literatur, Verkehrstechnik, Grüne Post, Reichssportblatt (samt Turnzeitungen), Sirene, Koralle, Das Blatt der Hausfrau, sämtliche Modealben und Sonderhefte, Neue Modenwelt, Berliner Volks-Zeitung, Deutsche Romanpost

Bis zum Kriegsende 1945 wurden noch gedruckt:

Berliner Morgenpost, Berliner Illustrirte Zeitung, Deutsche Allgemeine Zeitung, Das 12Uhr-Blatt, Das Reich, Signal. Auch der Buchverlag, der Fachverlag (Bauwelt und Fachbücher) und das Schnittmustergeschäft produzierten bis zum Kriegsende.

In der Büchersparte waren vor allem populärwissenschaftliche und kriegsverherrlichende Werke erfolgreich. In die letztere Kategorie gehörten etwa Kameraden im Morgenrot (1941) von Fritz Fillies oder Der Geist der siebenten Kompanie (1942) von Gino Forst von Moellewitz. ${ }^{83}$ Auch viele der scheinbar ideologisch nicht vereinnahmten Unterhaltungsfilme, die während der NS-Zeit veröffentlicht wurden, basierten auf Romanreihen des Deutschen Verlags. ${ }^{84}$

Bis weit in die Kriegszeit hinein lief die Produktion des Deutschen Verlags also auf Hochtouren - selbst nachdem das Berliner Stadtzentrum Ende November 1943 durch mehrere Bombenangriffe schwere Verheerungen erlebt hatte. Noch am 15. März 1944 meldete Wießner beachtliche Druckauflagen: Bei der Berliner Illustrirten waren es 2,6 Mio. Exemplare, bei der Sirene 1,8 Mio., beim Reich 1,4 Mio. und bei der Grünen Post immerhin noch 677.000 Exemplare. ${ }^{85}$

Natürlich arbeiteten im Deutschen Verlag auch Zwangsarbeiter, eigens für sie errichtete man ein Lager in der Besselstraße, also ganz in der Nähe des Stammhauses in der Kochstraße. Zudem gab es eine Baracke am Mariendorfer

82 Die bisher einzige Untersuchung zu dieser Publikation, deren Zielgruppe Evakuierte und Bombengeschädigte waren: Antes, Carolin: Die Deutsche Romanpost. In: „Der ganze Verlag ist einfach eine Bonbonniere“. Ullstein in der ersten Hälfte des 20. Jahrhunderts. Hrsg. von David Oels u. Ute Schneider. Berlin/München/Boston 2015 (Archiv für Geschichte des Buchwesens 10). S. $170-186$.

83 Mehr Beispiele bei Wippermann, Eule, S. 215.

84 Aus einer Festschrift, die anlässlich des 50. Geburtstags von Max Amann veröffentlicht wurde und die offenbar von Max Wießner persönlich verfasst worden war: Unbekannt: Deutscher Verlag 1934-1941. Berlin 1941, S. 39.

85 Siehe Mendelssohn, Zeitungsstadt, S. 549. 
Damm, gleich am Druckhaus Tempelhof. ${ }^{86}$ Im Dezember 1942 etwa wurden 400 Zwangsarbeiter aus Frankreich und der Ukraine unmittelbar in Deutschland „angeworben“. 87

Der Verlag hatte bei den Arbeitsämtern gezielt nach Hilfsarbeitern für die Setzerei, die Druckerei, die Buchbinderei, den Versand sowie für Enttrümmerungsarbeiten nachgefragt. ${ }^{88}$ Verlagsleiter Wießner teilte die Zwangsarbeiter ihrer Herkunft nach ein, in „Zivilarbeiter“ (Zivilisten aus europäischen Ländern, die unter deutscher Besatzung standen), „Internierte“ (italienische Soldaten, die ab September 1943 nach Deutschland deportiert worden waren) sowie „Ostarbeiter“ aus Polen, der Ukraine und Russland. Letztere wurden für die niedrigsten Arbeiten, etwa die Trümmerräumung, eingesetzt.

Das Ende des alten Berliner Zeitungsviertels lässt sich genau datieren: Die amerikanische Luftflotte bombardierte am Samstag, dem 3. Februar 1945, in zwei Wellen die Stadtmitte.

Getroffen wurden vor allem der Nordwesten Kreuzbergs sowie Berlin-Mitte und damit auch das Zeitungsviertel. Etwa 25.000 Menschen sollen an diesem Vormittag gestorben sein, rund 120.000 wurden obdachlos. Das Berliner Stadtschloss brannte aus, der Anhalter Bahnhof verschwand und 2.296 Bauten wurden völlig zerstört. ${ }^{89}$ Von den alten Verlagshäusern Ullstein, Mosse und Scherl blieben nur rauchende Mauerreste.

Diesen Angriff hatte das Druckhaus in Tempelhof relativ unbeschadet überstanden, doch in den letzten Kriegstagen geriet der „Rote Riese“ ins Visier des Artilleriefeuers. Am Nachmittag des 27. April erreichten die ersten sowjetischen Einheiten das Gebäude und besetzten es.

86 Siehe Bannehr, Eule, S. 101.

87 Hierzu Wippermann, Eule, S. 219.

88 Vgl. Lindner, Arisierung, S. 80, für nachfolgende Schilderung.

89 Siehe Smit, Erik, Staikos, Evthalia u. Dirk Thormann: 3. Februar 1945. Die Zerstörung Kreuzbergs aus der Luft. Hrsg. vom Kunstamt Kreuzberg. Berlin 1995, S. 12 f. 
